Board of Governors of the Federal Reserve System

International Finance Discussion Papers

Number 734

August 2002

THE INFLATION PERSISTENCE OF STAGGERED CONTRACTS

\author{
Luca Guerrieri
}

NOTE: International Finance Discussion Papers are preliminary materials circulated to stimulate discussion and critical comment. References in publications to International Finance Discussion Papers (other than an acknowledgement that the writer has had access to unpublished material) should be cleared with the author or authors. Recent IFDPs are available on the Web at www.federalreserve.gov/pubs/ifdp/. 


\title{
The Inflation Persistence of Staggered Contracts
}

\author{
Luca Guerrieri *
}

\begin{abstract}
One of the criticisms routinely advanced against models of the business cycle with staggered contracts is their inability to generate inflation persistence. This paper finds that staggered contracts à la Taylor are, in fact, capable of reproducing the inflation persistence implied by U.S. data. Following Fuhrer and Moore, I capture the moments that the contract specification needs to replicate by using the correlograms from a small vector autoregression (VAR) that includes inflation among the endogenous variables. A simple structural model substitutes the inflation equation from the VAR with the contract specification. I estimate the contract parameters in the structural model by maximum likelihood. The correlogram for the endogenous variables from the estimated structural model, including that for inflation, are very close to the correlograms from the VAR (and are contained within their 90\% confidence intervals). By the same metric, where Taylor contracts do not fare well is in reproducing the cross-correlations between inflation and output.
\end{abstract}

Keywords: maximum likelihood, Phillips curve.

${ }^{*}$ Correspondence: Board of Governors of the Federal Reserve System, Washington D.C. 20551-0001. Telephone (202) 452 2550. Fax (202) 872 4926. E-mail Luca.Guerrieri@frb.gov. I am grateful to David Bowman, Joe Gagnon, Dale Henderson and Andy Levin for advice and encouragement. While writing this paper, I had useful conversations with Paul Bergin, Jason Brown, Chris Erceg, Jeff Fuhrer, Chris Gust, Peter Ireland, John Roberts, Argia Sbordone, Ralph Tryon, and Jonathan Wright. I also need to thank the participants of the International Finance Workshop for their insightful comments. Remaining errors are my own. The views in this paper are solely the responsibility of the author, and should not be interpreted as reflecting the views of the Board of Governors of the Federal Reserve System, or of any other person associated with the Federal Reserve System. 


\section{Introduction}

The study of the Phillips curve has been central to macroeconomics since Phillips (1958) identified a negative correlation between inflation and unemployment. King and Watson (1994) give a comprehensive discussion of the evolution of the traditional empirical literature.

Nominal rigidities have become the standard theoretical underpinning of what Galí and Gertler (1999) called "the new Phillips curve". They used limited information estimation to show that a standard contracting specification provides a good description of the U.S. data. Sbordone (2002) validated the results of Galí and Gertler (1999) by using an alternative estimation method that follows Campbell and Shiller (1988). Galí, Gertler, and LópezSalido (2001a) suggested that the staggered contract mechanism fits the European data possibly even better than the U.S. data. Rudd and Whelan (2001) question the power of tests employed by Galí and Gertler (1999) and Galí, Gertler, and López-Salido (2001a). Galí, Gertler, and López-Salido (2001b) address these concerns.

The results of Fuhrer and Moore (1995) stand out in the growing empirical literature on the new Phillips curve. They showed that the staggered price mechanism of Taylor (1980) (henceforth, referred to as "standard") is not capable of generating the inflation persistence that they observed in the U.S. data. Fuhrer and Moore showed that an alternative contracting specification (henceforth, referred to as "relative"), first introduced by Buiter and Jewitt (1981), fares much more favorably in fitting the U.S. data. This alternative specification postulates that, when choosing a contract wage, workers care about the relative remuneration with respect to other outstanding contracts. This has the practical effect of introducing an extra lag of inflation in the implied Phillips curve, which accounts for its ability to generate greater persistence. The results of Fuhrer and Moore (1995) continue to be greatly influential. Representative recent papers that list it as a motivation are Calvo, Celasun, and Kumhof (2001), who postulate sticky inflation at the onset, and Mankiw and Reis (2002), who build on the work of Roberts (1997) in assuming sticky information.

The evaluation procedure of Fuhrer and Moore (1995) has two steps. First, a simple 
statistical model captures the properties of the data that the contracting specification needs to reproduce. The statistical model takes the form of an unconstrained vector autoregression (VAR) with output per person, inflation and the short-term interest rate as the endogenous variables. Then, the equation for inflation in the VAR is replaced with a contracting specification, thus generating a structural model where only the parameters in the contracting specification are unknown. Second, the structural parameters are estimated via maximum likelihood.

Coenen and Wieland (2000) followed the methodology of Fuhrer and Moore (1995) to calibrate a general equilibrium model of the Euro area. In line with Galí, Gertler, and López-Salido (2001a), they found that both the standard and the relative contracting specification "fit euro area data reasonably well."

The sample in Fuhrer and Moore (1995) spans the period from 1965 to 1993, thus including the oil crises of the 70s, as well as the Volcker disinflation. Evans and Wachtel (1977), Taylor (2000), and Cogley and Sargent (2000) documented that a high degree of inflation persistence is a characteristic of the late 1960s and 1970s, but not necessarily of the remaining postwar period. Erceg and Levin (2001) developped a model with standard contracts where agents use optimal filtering to disentangle persistent and transitory shifts in monetary policy. They attributed the observed persistence in inflation, following the Volcker disinflation, to uncertainty over monetary policy.

The purpose of this paper is to test whether or not the lower persistence of inflation found by other authors in the U.S. data for the 1980s and 1990s translates into significantly different estimates of the parameters in the standard and relative contract model. As a byproduct, this is also a test of whether the results of Fuhrer and Moore (1995) still hold true when using the additional data that have become available since the original publication of their study. Not only are longer time series available, but the series have been revised. The data that Fuhrer and Moore (1995) used come from the productivity release of the Bureau of Labor Statistics. Duke and Usher (1998) document the latest improvements to these series. 
Using the sample from 1980 to 2001, I find that relative contracts are able to reproduce the inflation persistence observed in the data. This is still true if the estimation sample starts in 1965q1 or in 1960q1. The results concerning relative contracts reported by Fuhrer and Moore (1995) still hold with updated data and longer series, and are resilient to introducing breaks in the linear detrending of output, as well as reestimation over smaller subsamples.

More surprisingly, I also find that standard contracts perform very well. The metric that I use to make these claims is the distance between correlograms for inflation, the interest rate and output coming from the VAR and the structural models. I compare the correlograms from the unrestricted VAR with the correlograms from the estimated structural model with standard contracts and with relative contracts. I find that the correlogram from the VAR for each of the three endogenous variables is close to the two structural counterparts across all the subsamples I consider. I compute the Monte-Carlo $90 \%$ confidence interval for the correlograms from the VAR. The correlograms for the two structural models invariably lie within the confidence bands. This is true not only for the benchmark sample 1980 to 2001, but also for extended samples going back to 1960 . Where Taylor contracts do not perform well is in reproducing the cross-correlations between inflation and output.

Focusing on the 1980s and 1990s, I estimate a change in the structural parameters of the two contracting models I consider. This shift is consistent with a lower persistence of the inflation series, but is not statistically significant.

In previous work, Guerrieri (2001), found that staggered contracts set up following Calvo (1983), produced a better fit to the U.S. data than staggered contracts of one single fixed duration à la Taylor. Similarly, Jadresic (1999) found that a trimodal distribution of contract durations fit the U.S. data better than a fixed contract duration. The contracts in this paper, by allowing the coexistence of multiple contract durations, follow more closely the setup of Taylor (1980). Yun (1996) showed how to reconcile contracts à la Calvo with a first order condition coming from a profit maximization problem. Chari, 
Kehoe, and McGrattan (2000), transferred the setup of Yun (1996) to contracts of fixed duration. In this paper I show how to allow for multiple contracts of fixed duration à la Taylor, in a way that can be mapped into a profit maximization exercise, and that is still parsimonious in terms of the size of the implied state space. This reinterpretation, can then be mapped into the setup of Fuhrer and Moore (1995). Allowing for a distribution of contract durations makes Taylor staggered contracts closer to the Calvo counterparts. The single contract duration is rejected by the data, substantiating that this development has empirical relevance.

The plan for the rest of the paper is as follows: in Section 2, I build some intuition for the difference between standard contracts and relative contracts; in Section 3, I lay out the methodology I used in the VAR estimation. In Section 4, I describe the structural estimation, and report the estimation results; and in section 5, I conclude.

\section{Comparing Standard and Relative Contracts}

Galí and Gertler (1999) gave a good review of the recent state of the literature. I will only attempt to summarize the salient points.

The structure behind the new Phillips curve is an environment of monopolistically competitive firms that are faced with a constraint on price adjustment. Following Taylor (1980), firms are allowed to reset their contract price every $n$ periods. Firms are otherwise symmetric in every other respect. At any period, $n$ overlapping contracts are in force.

Chari, Kehoe, and McGrattan (2000) showed that profit maximization implies a first order condition for a firm resetting its price at time t, that, by log-linearizing, leads to:

$$
P_{t}=\sum_{i=0}^{n-1} \frac{1}{n} E_{t}\left(\bar{P}_{t+i}+\gamma \tilde{Y}_{t+i}\right)
$$

$P_{t}$ is the $\log$ of the contract price set at time $t, \tilde{Y}_{t}$ is an output measure and $E_{t}$ denotes expectations conditional on the information set available at time $t$. This also happens to be be the contracting specification chosen by Taylor $(1980)^{1}$. The log of the aggregate price,

\footnotetext{
${ }^{1}$ This is indeed a special case of that model, for a particular set of contract weights. Taylor's paper focused on
} 
$\bar{P}_{t}$, is then given by:

$$
\bar{P}_{t}=\sum_{i=0}^{n-1} \frac{1}{n} P_{t-i}
$$

combining equation (1) and equation (2), setting $n=2$, allowing for the fact that under rational expectations $E_{t-1} P_{t}=P_{t}-\epsilon_{t}$ (where $\epsilon$ is a forecast error), and finally reworking the price equation in terms of inflation, denoted by $\pi_{t}$, one obtains the Phillips curve equation, which as shown in Appendix A, is given by

$$
\pi_{t}=E_{t} \pi_{t+1}+\gamma\left(\tilde{Y}_{t}+E_{t} \tilde{Y}_{t+1}+\tilde{Y}_{t-1}+E_{t-1} \tilde{Y}_{t}\right)-\frac{1}{4} \epsilon_{t}
$$

\subsection{The relative contract model}

Fuhrer and Moore (1995) argued that the persistence imparted to inflation by the standard contracting specification does not fit the U.S. inflation data as well as their relative specification. Their alternative model can be summarized by the following equations, where each variable is to be thought in log deviation from steady state. The contract equation is the following:

$$
P_{t}-\bar{P}_{t}=\sum_{i=0}^{n-1} \frac{1}{n} E_{t}\left(V_{t+i}+\gamma \tilde{Y}_{t+1}\right)
$$

where $P_{t}$ is the price contract that starts in period $t, \bar{P}_{t}$ is the aggregate price level, $\tilde{Y}_{t}$ is an output measure. The aggregate price level is still governed by equation (2). $V_{t}$ is a relative price index, that takes following form

$$
V_{t}=\sum_{i=0}^{n-1} \frac{1}{n}\left(P_{t-i}-\bar{P}_{t-i}\right)
$$

Then, for $n=2$, the Phillips curve equation implied by this contracting specification takes the form:

$$
\pi_{t}=\frac{1}{2}\left(\pi_{t-1}+E_{t} \pi_{t+1}\right)+\gamma\left(\tilde{Y}_{t}+E_{t} \tilde{Y}_{t+1}+\tilde{Y}_{t-1}+E_{t-1} \tilde{Y}_{t}\right)-\frac{1}{4} \epsilon_{t}
$$

staggered wages. The subsequent literature shifted the setup to staggered prices. Huang and Liu (2002) showed that the staggered wage interpretation allows one to escape the criticism of staggered contracts of Chari, Kehoe, and McGrattan (2000). 
Comparing equations (3) and (6), one can immediately see that the relative contract specification, for any given contract length, appends an extra lag of inflation to the Phillips curve equation.

\section{$2.2 \quad$ Allowing for multiple contract lengths}

Rather than maintaining that all contracts last $n$ periods, a more flexible setup would allow for a distribution of contract durations. Following Blinder (1994), one could also brand such a setup as more plausible. A simple way to model this distribution is to assume that when firms set a price, they face uncertainty over the contract duration. The price they set might be in force for any length of time between 1 and $n$ periods. Firms do know, however, the relevant probabilities. Then, let $\theta_{1}$ be the probability that a contract will be in force only one period, let $\theta_{2}$ be the probability that a contract will be in force for two periods, and so on. Let the vector $\theta$ summarize the relevant contract weights. The elements of $\theta$ are all non-negative and sum to 1 . Fixing the longest contract duration at four periods $(n=4)$, the aggregate price level becomes

$$
\bar{P}_{t}=\theta_{1} P_{t}+\theta_{2} \frac{1}{2} \sum_{i=0}^{1} P_{t-i}+\theta_{3} \frac{1}{3} \sum_{i=0}^{2} P_{t-i}+\theta_{4} \frac{1}{4} \sum_{i=0}^{3} P_{t-i}
$$

The setup of Fuhrer and Moore (1995) can be reinterpreted to conform to this setup. One way to impose some structure on the distribution of contract lengths would be to pick a functional form for the weights on contract prices in equation (7). Letting $f_{i}$ denote the weight on the contract price with lag $i$, equation (7) would then be rewritten as

$$
\bar{P}_{t}=\sum_{i=0}^{3} f_{i} P_{t-i}
$$

Fuhrer and Moore (1995) imposed that

$$
f_{i}=0.25+(1.5-i) s
$$

where $\mathrm{s}$ is the only parameter governing the shape of the distribution of contract durations. To be able to match a choice for $s$ into a vector $\theta, s$ needs to be contained in the interval 
Table 1: Mapping $s$ into $\theta$

\begin{tabular}{|c||c|c|c|c||c|c|c|c|}
\hline$s$ & $\theta_{1}$ & $\theta_{2}$ & $\theta_{3}$ & $\theta_{4}$ & $f_{0}$ & $f_{1}$ & $f_{2}$ & $f_{3}$ \\
\hline \hline 0 & 0 & 0 & 0 & 1 & 0.25 & 0.25 & 0.25 & 0.25 \\
\hline 0.06 & 0.06 & 0.12 & 0.18 & 0.63 & 0.34 & 0.28 & 0.22 & 0.16 \\
\hline 0.08 & 0.08 & 0.16 & 0.24 & 0.52 & 0.37 & 0.29 & 0.21 & 0.13 \\
\hline$\frac{1}{6}$ & $\frac{1}{6}$ & $\frac{1}{3}$ & $\frac{1}{2}$ & 0 & $\frac{1}{2}$ & $\frac{1}{3}$ & $\frac{1}{6}$ & 0 \\
\hline
\end{tabular}

between $^{2} 0$ and $\frac{1}{6}$. In Appendix B, I show how to map a choice for $s$ into a set of contract weights $\theta_{1}$ to $\theta_{4}$. In Table 1 , I perform this mapping for selected values of $s$. As shown, as $s$ decreases, the weight on the longer contracts increases. In this stochastic contract setup, the contract price rule for the standard model becomes

$$
P_{t}=\sum_{i=0}^{3} f_{i} E_{t}\left(\bar{P}_{t+i}+\gamma \tilde{Y}_{t+i}\right)
$$

while, for the relative contract setup, following Fuhrer and Moore (1995)

$$
P_{t}-\bar{P}_{t}=\sum_{i=1}^{3} f_{i} E_{t}\left(V_{t+i}+\gamma \tilde{Y}_{t+i}\right)
$$

where $V_{t}$ can be substituted into (11) from equation (5).

\subsection{Nesting the two models}

Let $\delta$ govern the fraction of agents using relative contracts. Then the standard and the relative contract models can be nested by letting the contract price equation become

$$
P_{t}-\delta \bar{P}_{t}=\sum_{i=1}^{3} f_{i} E_{t}\left(V_{t+i}^{n}+\gamma \tilde{Y}_{t+i}\right)
$$

where the index $V_{t}^{n}$ is given by

$$
V_{t}^{n}=\sum_{i=0}^{n-1} \frac{1}{n}\left(P_{t-i}-\delta \bar{P}_{t-i}\right)
$$

\footnotetext{
${ }^{2}$ This is equivalent to the condition imposed by Fuhrer and Moore (1995) that the polynomial in the lag operator used to rewrite the aggregate price equation be invertible.
} 


\section{VAR estimation}

In order to assess the properties of the data that the contracting specification needs to reproduce I rely on a simple statistical model that takes the form of a VAR. Detrended output and inflation are the series of interest. Following Bernanke and Blinder (1992), Fuhrer and Moore (1995) and Coenen and Wieland (2000), I include the short term nominal interest rate in the VAR to help in the formation of output expectations. Thus the three endogenous variables in the VAR are detrended log of output, inflation and the short term interest rate.

Just as Fuhrer and Moore (1995) the series for the above variables come from the productivity release of the Bureau of Labor Statistics. While the interest rate series goes back to 1934, the output and price series start in the first quarter 1947. For the VAR estimation I discard the first part of the sample and take the first quarter of 1960 as the starting date for the analysis. I keep this first portion of the data as a presample, that I exploit later in the maximum-likelihood estimation of the structural parameters.

The measure of output that I consider is log of the nonfarm business output per person. The measure of inflation comes from a quarterly difference in the log of the nonfarm business output deflator. Finally the interest rate series is the 3 month treasury bill rate from the secondary market quoted on a discount basis.

I linearly detrend the output measure ${ }^{3}$ In the detrending, I have considered both single as well as multiple trends. I have considered breaks in 1983q1, which coincides with the end of Volcker's disinflation program, as an alternative, as well as 1992. The additional trends do not appear to affect the results. Here, I report only the results using one trend.

To decide the number of lags for the endogenous variables in the VAR equations I followed the general-to-specific approach. I started with a specification that included eight lags. I reduced this number, until the parameters on the longest lag were jointly significant across equations, and the residuals were uncorrelated. To test for correlation, I used a

\footnotetext{
${ }^{3}$ While one-sided filtering would be more rigorous, I use linear detrending procedure to ensure comparability with the results of Fuhrer and Moore (1995). I reserve the one-sided-filtering refinement to possible extensions of this paper.
} 
Portmentau test on lag 12. I settled on a VAR specifications that included three lags of all the endogenous variables. The VAR structure on which I settle has the form

$$
\begin{aligned}
\tilde{Y}_{t} & =\sum_{i=1}^{3} C_{y, 1, i} \tilde{Y}_{t-i}+C_{r, 1, i} r_{t-i}+C_{\pi, 1, i} \pi_{t-i}+\epsilon_{y, t} \\
r_{t} & =\sum_{i=1}^{3} C_{y, 2, i} \tilde{Y}_{t-i}+C_{r, 2, i} r_{t-i}+C_{\pi, 2, i} \pi_{t-i}+\epsilon_{r, t} \\
\pi_{t} & =\sum_{i=1}^{3} C_{y, 3, i} \tilde{Y}_{t-i}+C_{r, 3, i} r_{t-i}+C_{\pi, 3, i} \pi_{t-i}+\epsilon_{\pi, t}
\end{aligned}
$$

where $r_{t}$ is the short-term interest rate. The intercept term is excluded from the VAR structure to ensure a zero-inflation steady state, consistent with the two contracting specifications in this paper ${ }^{4}$.

When varying the sample length, I kept the VAR structure fixed. For reasons of space, I do not report all the coefficient estimates over the various subsamples I consider. I show the correlograms for the endogenous variables in Figure 1(this figure also includes the correlograms from the structural estimation described below). The correlogram has the advantage over impulse response functions of not requiring an identification scheme. I also report a $90 \%$ confidence interval around the correlograms. This is calculated using the Monte Carlo procedure described by Christiano, Eichenbaum, and Evans (1999).

\section{Structural estimation}

In order to estimate the structural parameters in the standard and in the relative contracting specification, I replace the the inflation equation in the VAR described in equations

\footnotetext{
${ }^{4}$ The parameter estimates for the VAR are relegated to an appendix. A likelihood ratio test confirms the validity of the restriction that the constant term be zero. The conclusions reported below are resilient to reintroducing a constant in the VAR. Excluding the constant does affect the shape of the correlogram for inflation and the interest rate from the VAR, depicted in Figure 1. Without a constant, the inflation persistence implied by the VAR appears to be higher, thus making the task for the structural model harder, given the prior, from Fuhrer's and Moore's work, that the structural model is not capable of reproducing the inflation persistence in the data.
} 
(29) to (31) with the relevant contract equations. I link prices to inflation by using

$$
\pi_{t}=4\left(\bar{P}_{t}-\bar{P}_{t-1}\right)
$$

Therefore, in the case of standard contracts, I call structural model the system of equations (10), (8) and (17), plus (29) and (30) from the VAR.

In the case of relative contracts, I call structural model the system of equations (11), (8) and (17), plus (29) and (30) from the VAR. For the purposes of estimation, I augment the contract price equation in both structural models with an observational error that I call $\epsilon_{P, t}$.

In both cases, the state space is given by $X_{t} \equiv\left(\bar{P}_{t}, \pi_{t}, P_{t}, \tilde{y}_{t}, r_{t}\right)^{\prime}$. For any choice of the parameters $\gamma$ and $s$, by standard methods, I can find the $\operatorname{AR}(1)$ representation for the variables in the state space, which can then be rewritten as

$$
X_{t}=A_{1} X_{t-1}+A_{2} X_{t-2}+A_{3} X_{t-3}+C \epsilon_{t}
$$

where $\epsilon_{t}=\left(\epsilon_{y, t}, \epsilon_{r, t}, \epsilon_{P, t}\right)^{\prime}$, while $A_{1}, A_{2}, A_{3}$, and $B$ are conformable matrices of coefficients (which can be thought of as functions of $s$ and $\gamma$ ). This system of equations, however, still holds two identities. I then split the state space $X_{t}$ into two parts $S_{t}$ and $Z_{t}$. $S_{t}$ is defined as $S_{t} \equiv\left(\bar{P}_{t}, P_{t}\right)^{\prime}$, while $Z_{t}$ is defined as $Z_{t} \equiv\left(\tilde{Y}_{t}, r_{t}, \pi_{t}\right)^{\prime}$. I can then rewrite equation (18) as

$$
Z_{t}=\tilde{A}_{1} Z_{t-1}+\tilde{A}_{2} Z_{t-2}+\tilde{A}_{3} Z_{t-3}+\tilde{B}_{1} S_{t-1}+\tilde{B}_{2} S_{t-2}+\tilde{B}_{3} S_{t-3}+\tilde{C} \epsilon_{t}
$$

To form the maximum likelihood function, I follow Harvey (1981), and condition on the first observation. I use the innovation representation of equation (19), assuming that $\epsilon_{t}$ is identically and independently distributed across time as normal. To form the likelihood, the last hurdle to overcome is that the contract price $P_{t}$ is unobserved. To remedy this, I adopt the following procedure. I assume that $P_{t}$, prior to 1947 , is in steady state. Given a choice for $\gamma$ and $s$, I use equation (19) to back out $\epsilon_{t}$. Using equations (18) and (19) I can then dynamically generate a series for $P_{t}$ and $\epsilon_{t}$. In order to dilute the assumption that $P_{t}$ be in steady state prior to 1947, I use data for the period between 1947 and 1960 
as a presample, with the sole purpose of initializing the value of $P_{t}$. I have used Monte Carlo experiments to confirm that after a period of 13 years, the initial value of $P_{t}$ becomes irrelevant. I maximize the likelihood using a Newton-Raphson based algorithm. To verify that the output of the algorithm maximizes the likelihood function, I use a linear-search procedure.

\subsection{Estimation Results}

The estimation results are summarized in Tables 2 to 4 . Table 2 reports the estimates for the relative contract model. Regressions 1 to 3 differ by the starting date of the sample. In regression 1, whose sample starts in 1980, $s$, the parameters governing the distribution of contract durations, is estimated at 0.0460 , with a standard error of 0.0149 . The implied distribution of contract durations is the following: $5 \%$ of contracts last one quarter, $9 \%$ two quarters, $14 \%$ three quarters, $72 \%$ four quarters. The weight of the output measure in the contract equations, $\gamma$, is estimated at 0.0425 with a standard error of 0.0161 . Both estimates are highly statistically significant. The variation in $s$ over different samples is not statistically significant. The estimate of $\gamma$ drops in Regression 2, when the sample starts in 1965q1, and in Regression 3, when the sample starts in 1960q1 ${ }^{5}$. This is consistent with a higher persistence of the inflation process in the 1960s and 1970s. A Portmenteau test on the residuals of this regression (one equation at a time), whose $\mathrm{Q}(12)$ statistics are reported in Table 5, rejects the null hypothesis of white noise disturbances at conventional significance levels.

Table 3 reports the estimates for the relative contract specification. For Regression 1, whose sample spans 1980q1 - 2001q4, the estimate for $s$ is 0.0895 , with a standard deviation of 0.0298. Over the longer samples, the estimates for s and gamma, are not statistically significantly different.

\footnotetext{
${ }^{5}$ Using the sample from 1965 to 1993 (as Fuhrer and Moore were constrained to do), I can obtain estimates of the parameters for the relative contract model, but not for the standard model. These estimates are in line with the ones originally reported by Fuhrer and Moore (1995).
} 
Table 4 reports the estimates for a contracting specification that nests both the relative and the standard model. The fraction of agents adopting relative contracts, $\delta$, is estimated in the order of $80 \%$ regardless of the start of the sample. The estimate is statistically significant at standard confidence levels.

Figure 1 compares the correlograms for inflation, the output measure and the interest rate obtained from three sources: the VAR, the estimated structural model with standard contracts, and the estimated structural model with relative contracts. The sample period used is that of regression 1, from 1980q1 to 2001q4. Figures 2 and 3 repeat the comparisons respectively for the sample period 1965q1-2001q4 and for 1960q1-2001q4. Across samples, one can see that the correlogram for inflation for both relative and standard contracts is close to the correlogram for the VAR and is contained within the Monte-Carlo $90 \%$ confidence interval for the correlogram for the VAR.

Figures 4 to 6 compare the fitted values for inflation from the structural model with relative contracts, and from the structural model with standard contracts with the actual values for inflation. Each of these figures focuses on a different sample. Both models appear to perform satisfactorily across samples. Especially for the sample 1980q1-2001q4, it is hard to distinguish the performance of the two models.

Using the information in Tables 2 to 4, one can set up a likelihood ratio test for the restriction that the nested structural model only includes either the standard or the relative contract specification. The standard model is rejected, while the relative model fails to be rejected at conventional significance levels. At first, in light of the comparisons of the correlograms in Figures 1 and 3, this finding appears surprising. In those figures, the performance of standard contracts appeared hardly distinguishable from the performance of relative contracts. Figure 7 provides an explanation for the results of the likelihood ratio tests. In the case of the cross-correlogram for inflation on lagged output, and for output on lagged inflation, the standard model at lags 1 to 5 , lies well outside the $90 \%$ confidence interval. It is on these dimensions that the likelihood test is penalizing the standard contract specification. This provides an explanation for why the proportion of 
relative contracts in the standard model is estimated as being so high, as well as why the standard model is rejected when performing a likelihood-ratio test. Figures 8 and 9 confirm that the same finding applies when the sample starts in 1965q1 or 1960q1, respectively.

In the light of figures 7 to 9, the Standard model performs satisfactorily in terms of reproducing the inflation persistence implied by the correlogram from the VAR. Where it is not performing as well as the relative contract model is in reproducing the comovements between output and inflation.

\subsection{Comparing Impulse Response Functions}

Fuhrer and Moore (1995) closed their model by estimating a VAR in output, inflation and the interest rate. This is the way I proceed for the purposes of estimating the unknown parameters in the contract equations. To understand the differences in the standard and relative contracts, instead of pursuing this route, one could more simply complete the model by following Taylor (1980), specifying equations for the demand and supply of money. It is easier to examine the differences imparted by the choice of contracting specification when the response of money is kept constant. This could not be achieved with an interest rate reaction function. Thus, let the demand for nominal money balances, $M_{t}$ take the form

$$
M_{t}=P_{t}+y_{t}
$$

And let money supply be described by

$$
M_{t}=M_{t-1}+\mu_{t}
$$

where $\mu_{t}$, the rate of growth of money supply, is given by $\mu_{t}=\rho \mu_{t-1}+\epsilon_{t}$ and $\epsilon_{t}$ is an i.i.d. error term ${ }^{6}$. One is now in a position to simulate the effects of shocks in the two models so as to assess the persistence properties of each specification. An area where one would expect the difference between the two contracts to emerge is in the response to monetary shocks.

\footnotetext{
${ }^{6}$ The money supply equation adopted here comes from Christiano, Eichenbaum, and Evans (1998) who argue that this is a good approximation to money supply for both M1 and M2 in the U.S., as long as $\rho$ is chosen to be close to 0.5 .
} 
I have performed a battery of tests, using temporary and permanent, announced and unannounced shocks to the rate of growth of money supply as well as to the level of money. In Figure 10 and 11, I report the impulse response functions for an unannounced shock to the rate of growth of money supply. The intuition gained in this case holds true for all the other shocks I considered. Holding the distribution of contract durations constant, the choice of $\gamma$, the weight on output in the contract equation, governs the persistence of inflation that the two contracting specifications can yield. Figures 10 and 11 differ by the choice of values for $\gamma$. Comparing Figures 10 and 11 one can see that the lower the value of $\gamma$, the greater the persistence. The path for inflation does look different whether one uses standard of relative contracts, however, it seems hard to draw any conclusions about the relative persistence.

Varying the value of $s$, not surprisingly, also affect the path for inflation. Lower values of $s$, by placing a greater weight on longer contracts, yield a more persistent response of inflation. In the light of this analysis, for the purposes of generating greater inflation persistence, given the choice of $n$, and $\gamma$, one would then replace standard contracts with relative contracts if lowering s did not produce enough extra persistence.

\section{Conclusion}

I have used a simple VAR to capture the properties of the data that a contract model needs to reproduce. My estimation results indicate that the contract model of Taylor (1980) performs as well as the relative contract model featured in Fuhrer and Moore (1995) at reproducing the inflation persistence observed in the data. Both types of contract specifications come close to replicating the second moments captured by a simple, nonstructural VAR.

Overall, the relative contract model does fit the data better than the standard contract model. However, the capacity to generate inflation persistence does not appear to be the major difference driving the results. The cross-correlograms for inflation and output, at 
small lags, are where I observe a better performance for the relative contract model.

When limiting the estimation sample to the 1980s and 1990s, I find that parameters for both contract models shift consistently with lower inflation persistence. However, this shift is statistically significant only for the case of standard contracts.

I read the estimation results in this paper as supporting that the standard staggered contract model of Taylor (1980) is perfectly adequate to capture the inflation persistence in the U.S. data. To explain the inflation behavior observed in the late 1960s and 1970s, it seems more appropriate to build extra structure to the model, rather than requiring that the contract model be able to explain a higher degree of inflation persistence. 

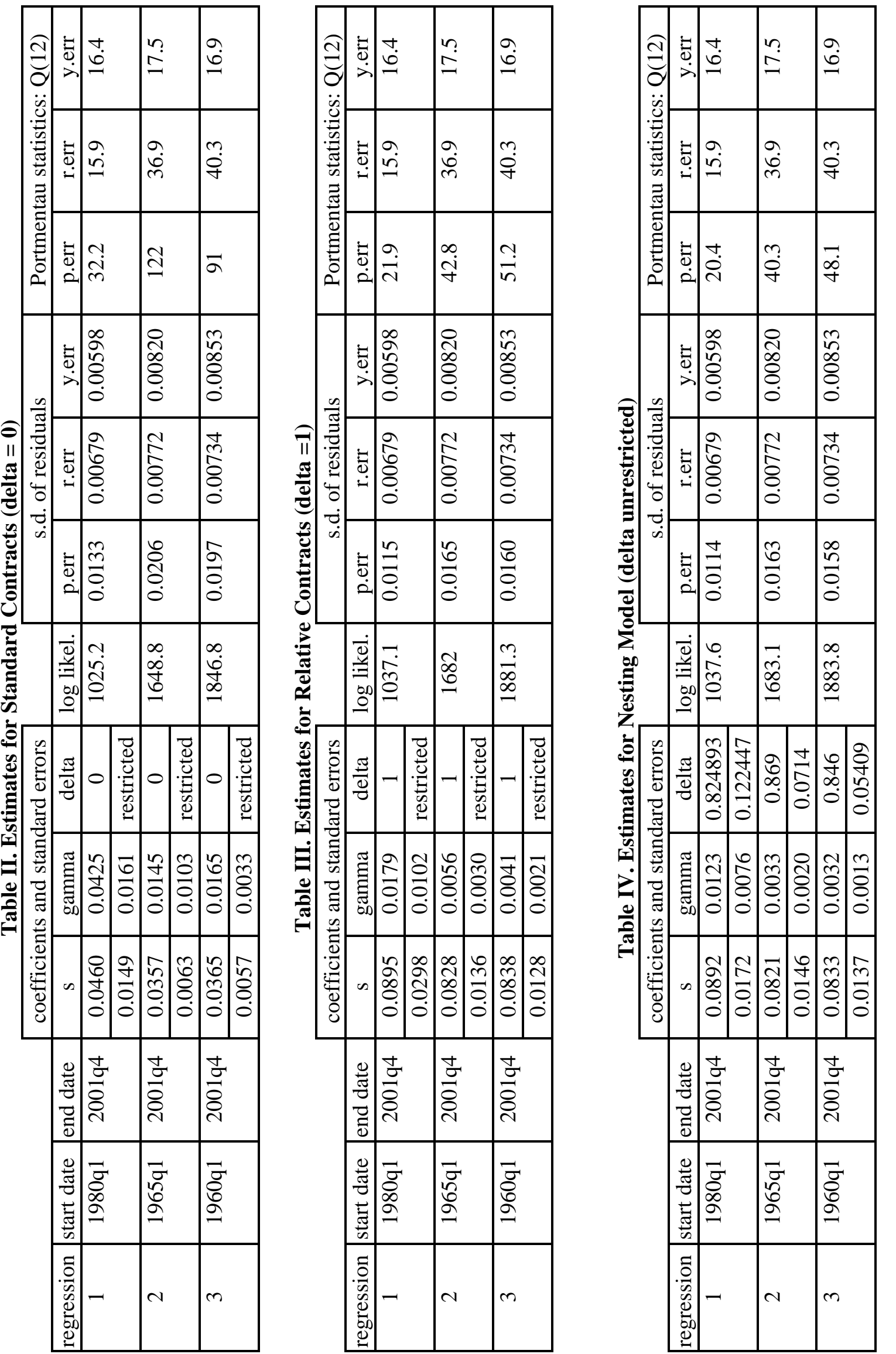

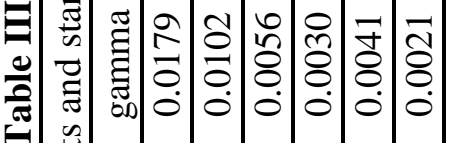

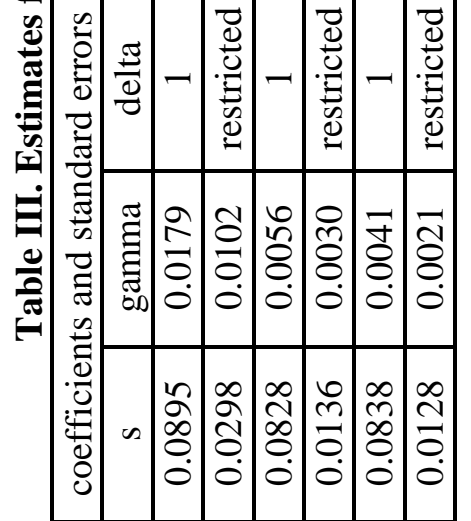

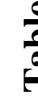

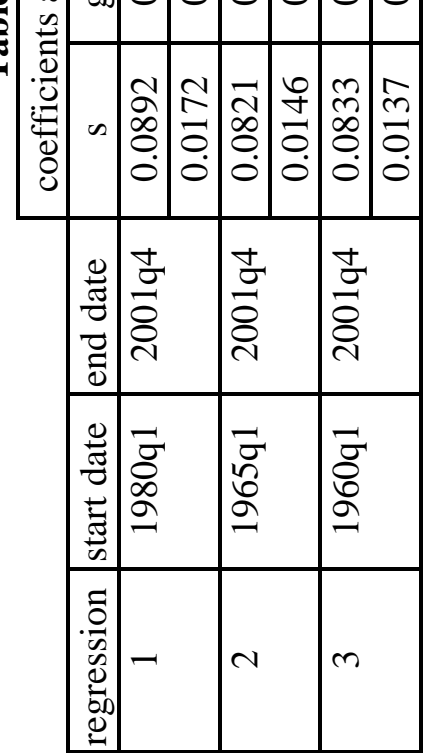


Figure 1: Correlogram for Regression 1 (1980q1 - 2001q4) Correlogram for Inflation
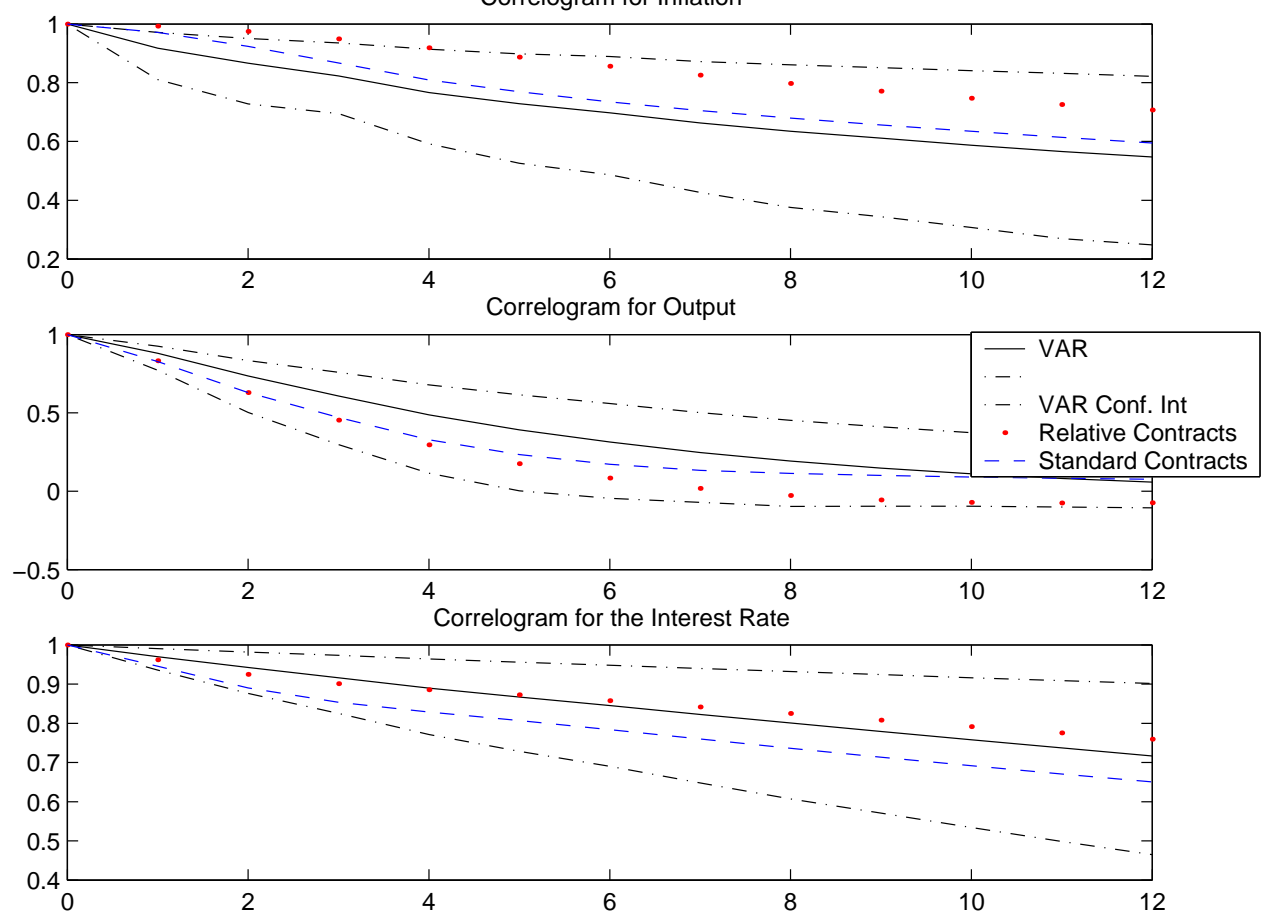

Figure 2: Correlogram for Regression 2 (1965q1 - 2001q4)
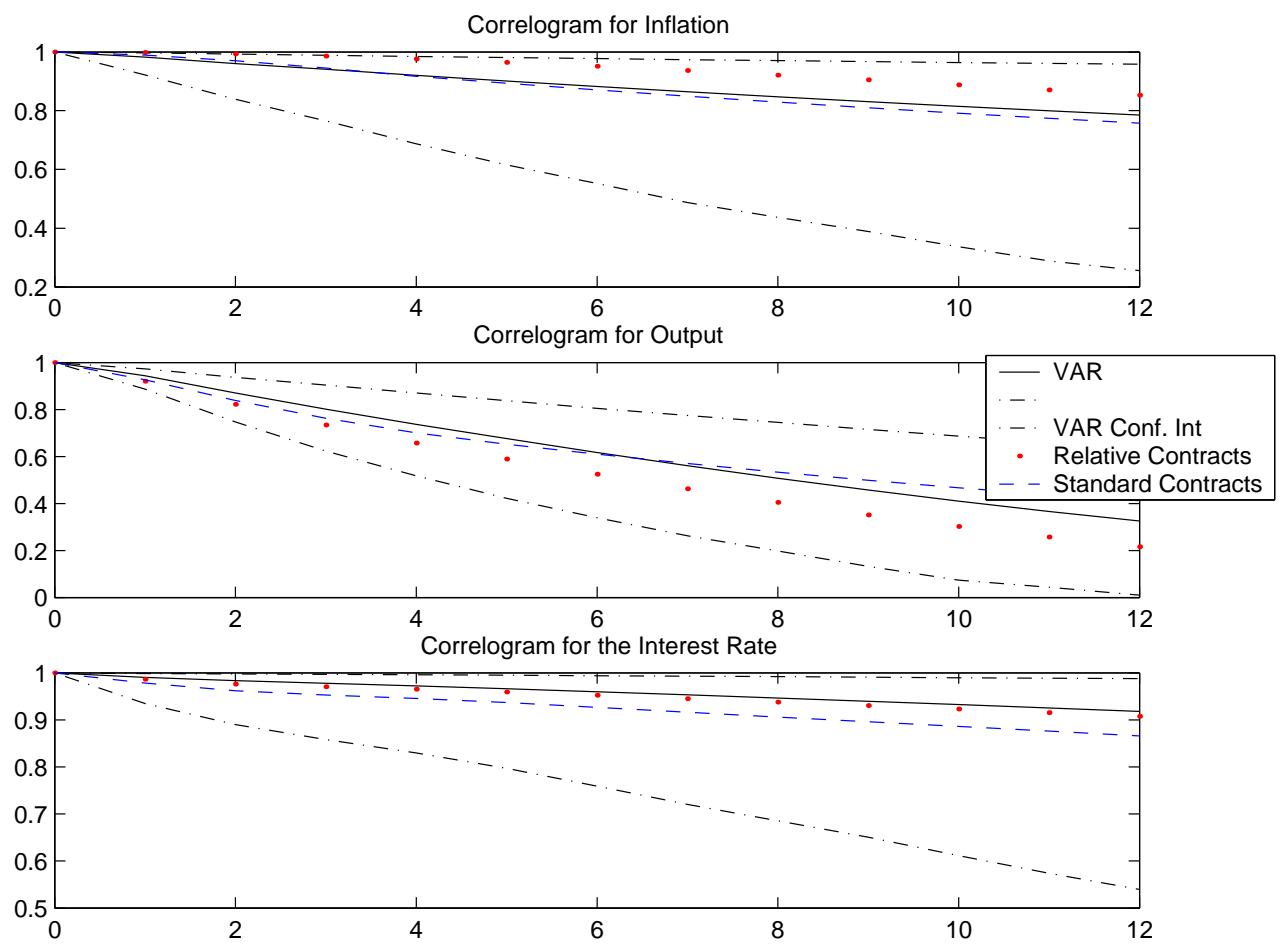
Figure 3: Correlogram for Regression 3 (1960q1 - 2001q4)
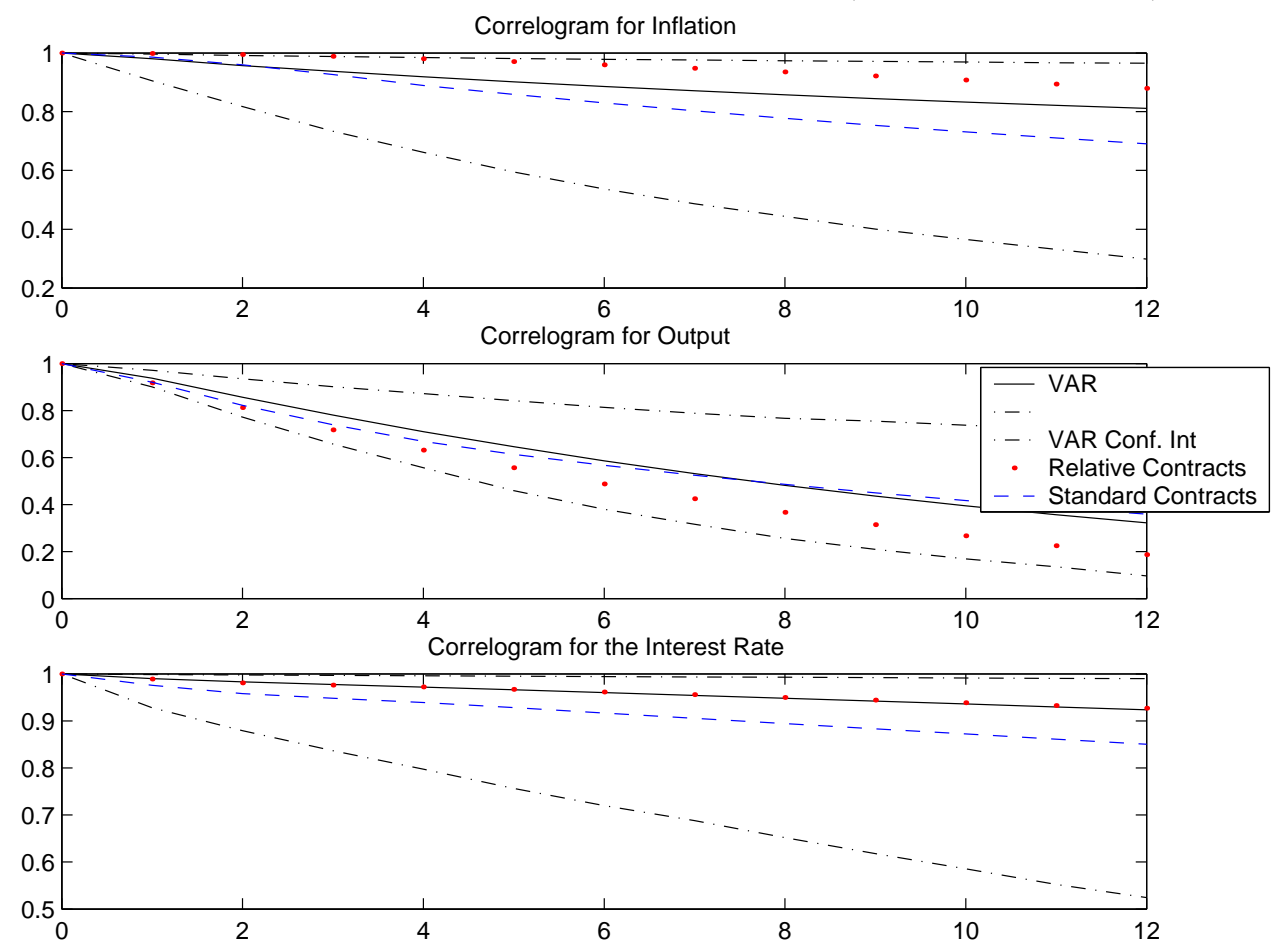
Regression 1: 1980q1 to 2001q4

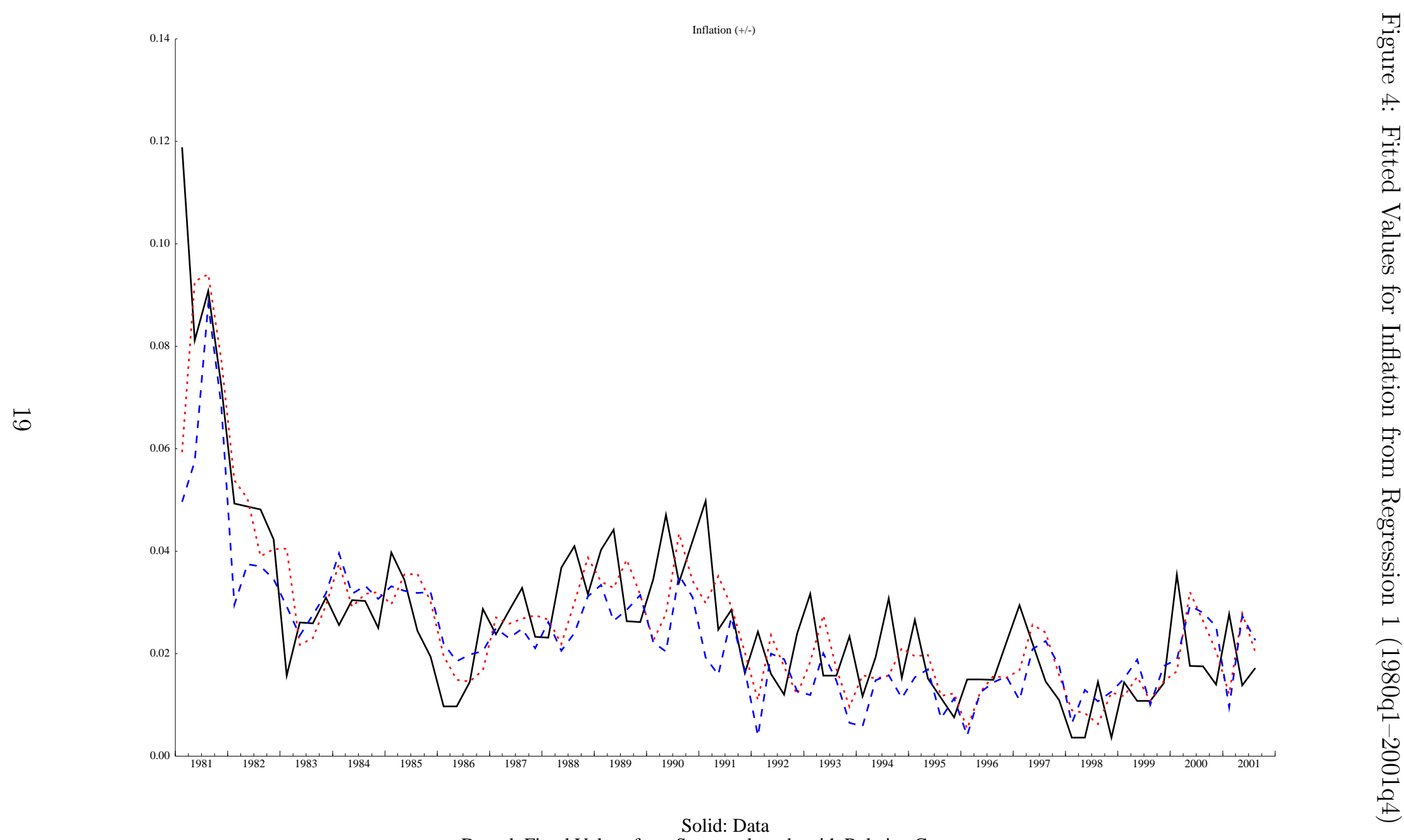

Dotted: Fitted Values from Structural mode with Relative Contracts Dashed: Fitted Values from Structural model with Taylor Contracts 
Regression 2: 1965q1 to 2001q4

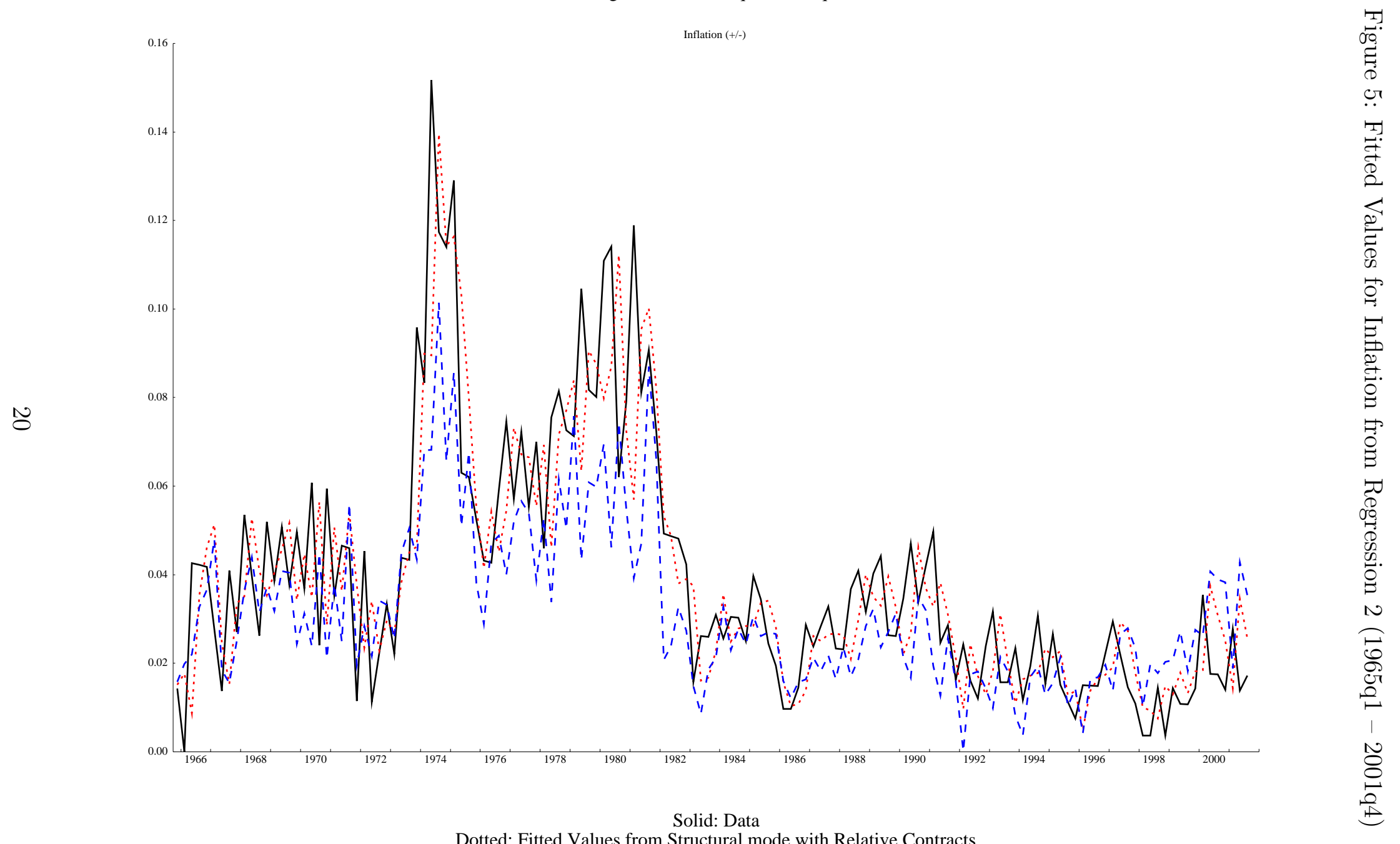

Dotted: Fitted Values from Structural mode with Relative Contracts

Dashed: Fitted Values from Structural model with Taylor Contracts 
Regression 3: 1960q1 to 2001q4

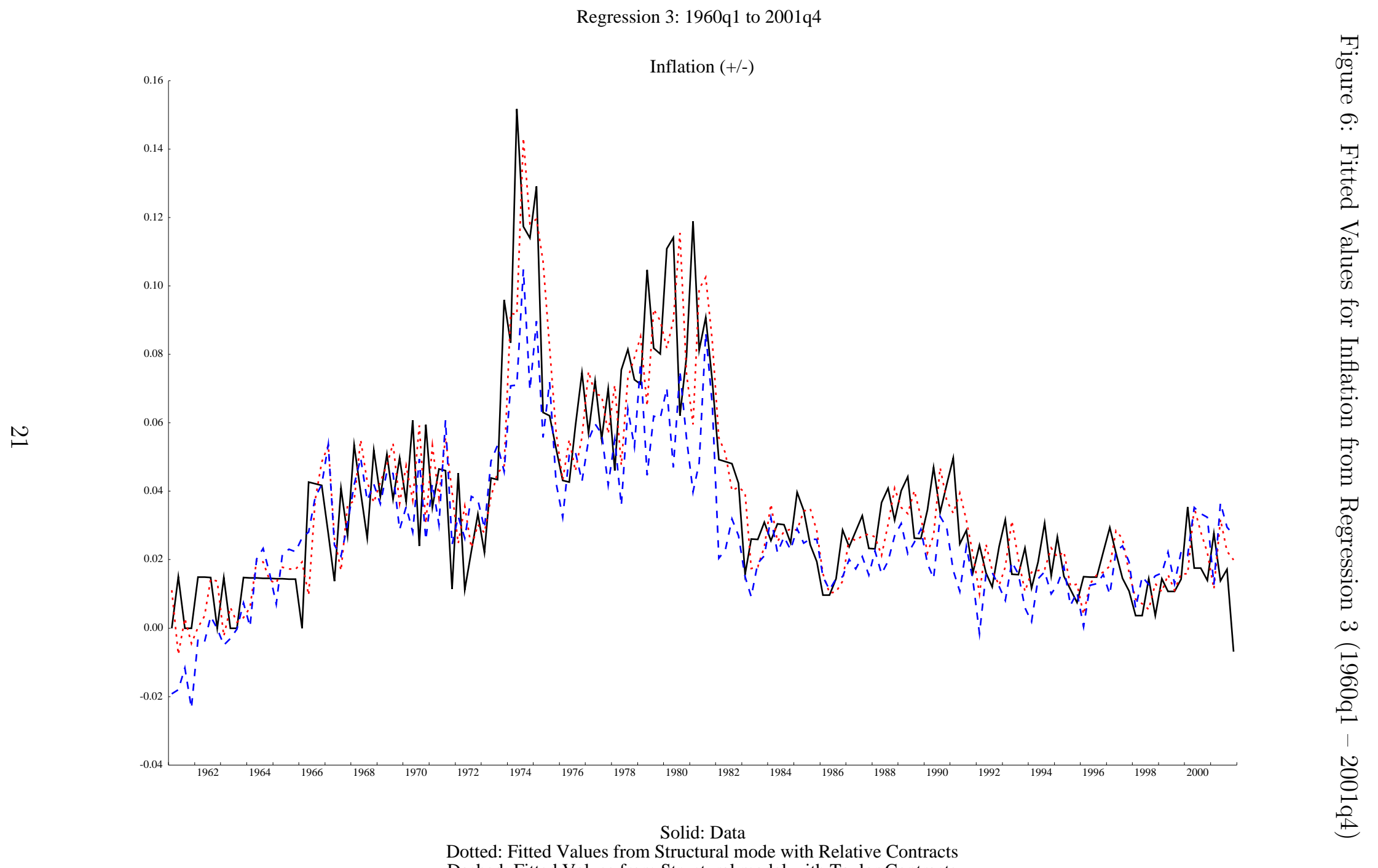

Dotted: Fitted Values from Structural mode with Rela

Dashed: Fitted Values from Structural model with Taylor Contracts 
Figure 7: Comparing cross-correlograms for Regression 1 (1980q1 - 2001q4)
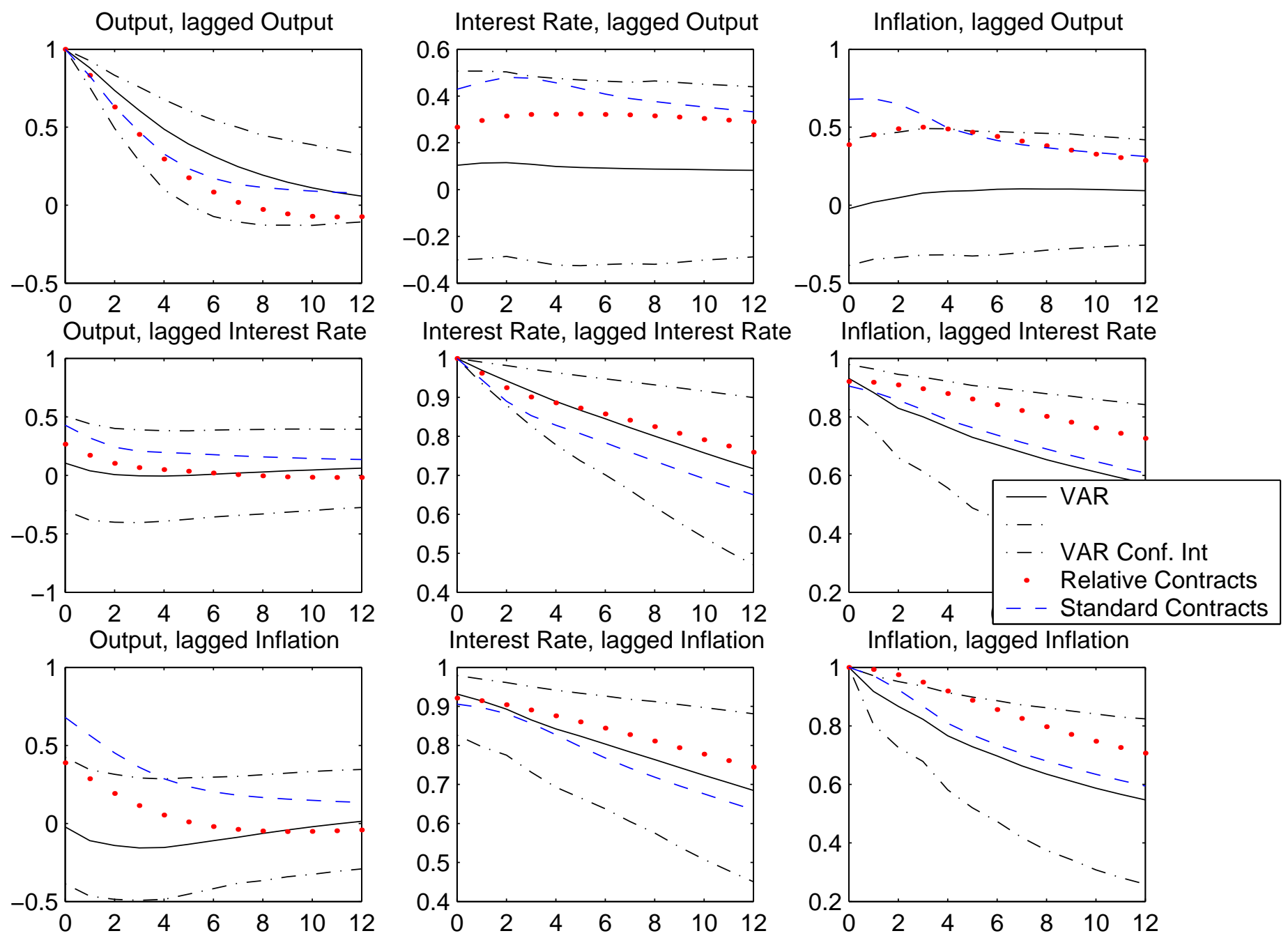
Figure 8: Comparing cross-correlograms for Regression 2 (1965q1 - 2001q4)
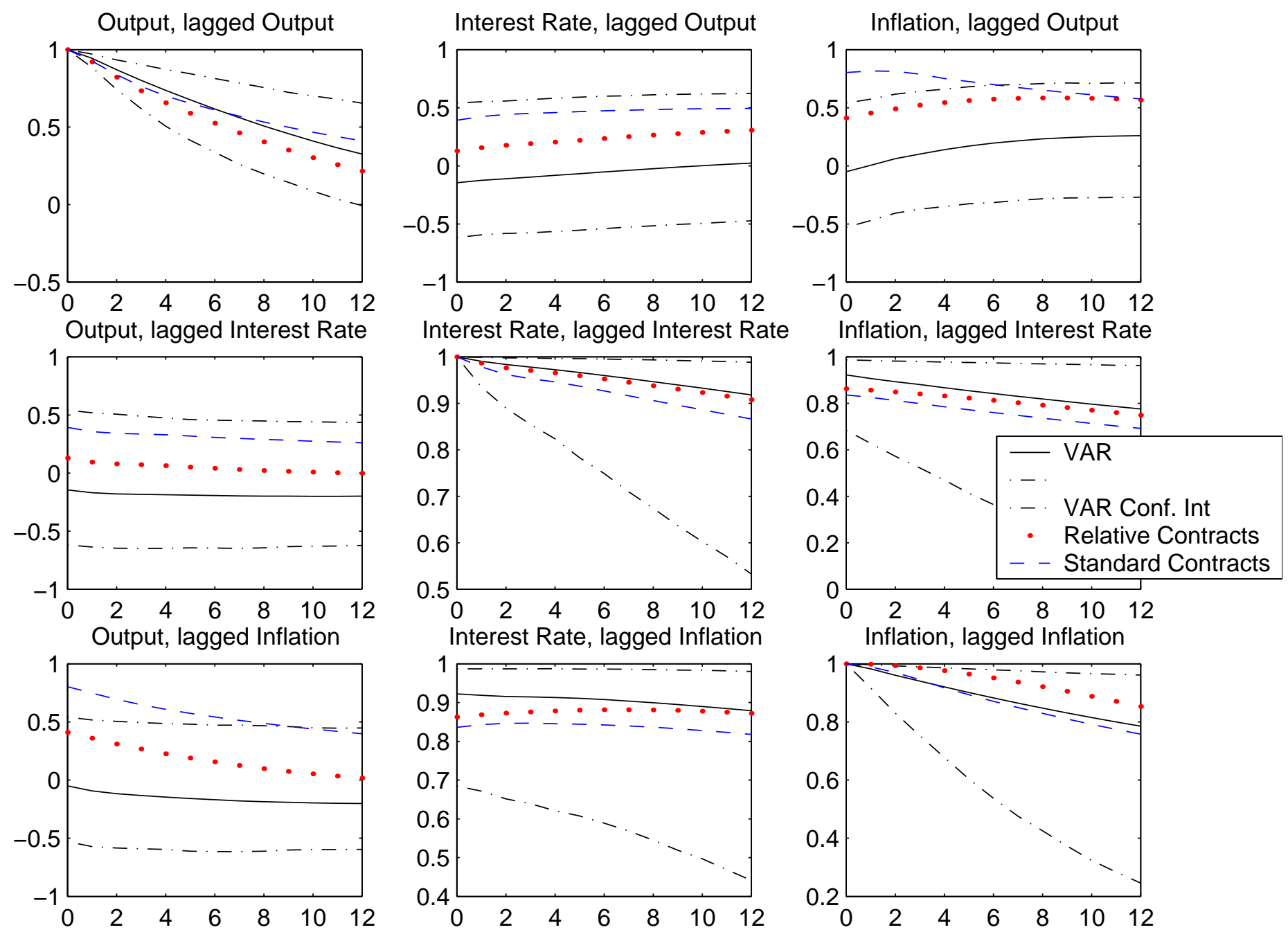
Figure 9: Comparing cross-correlograms for Regression 3 (1960q1 - 2001q4)
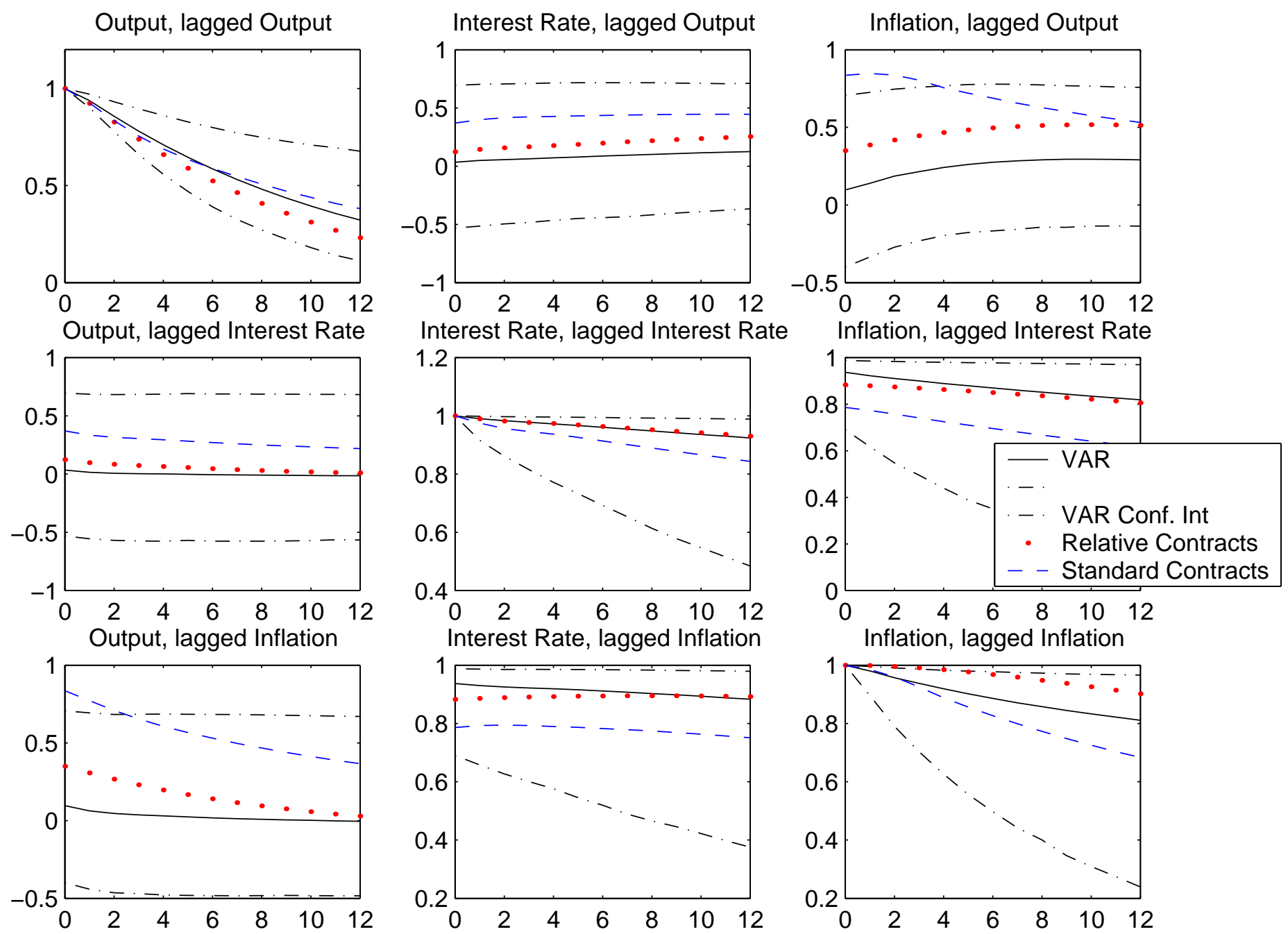
Figure 10: Response to an unannounced shock to the rate of growth of money supply.

Gamma $=0.004, S=0.08$

Percentage Change from Baseline
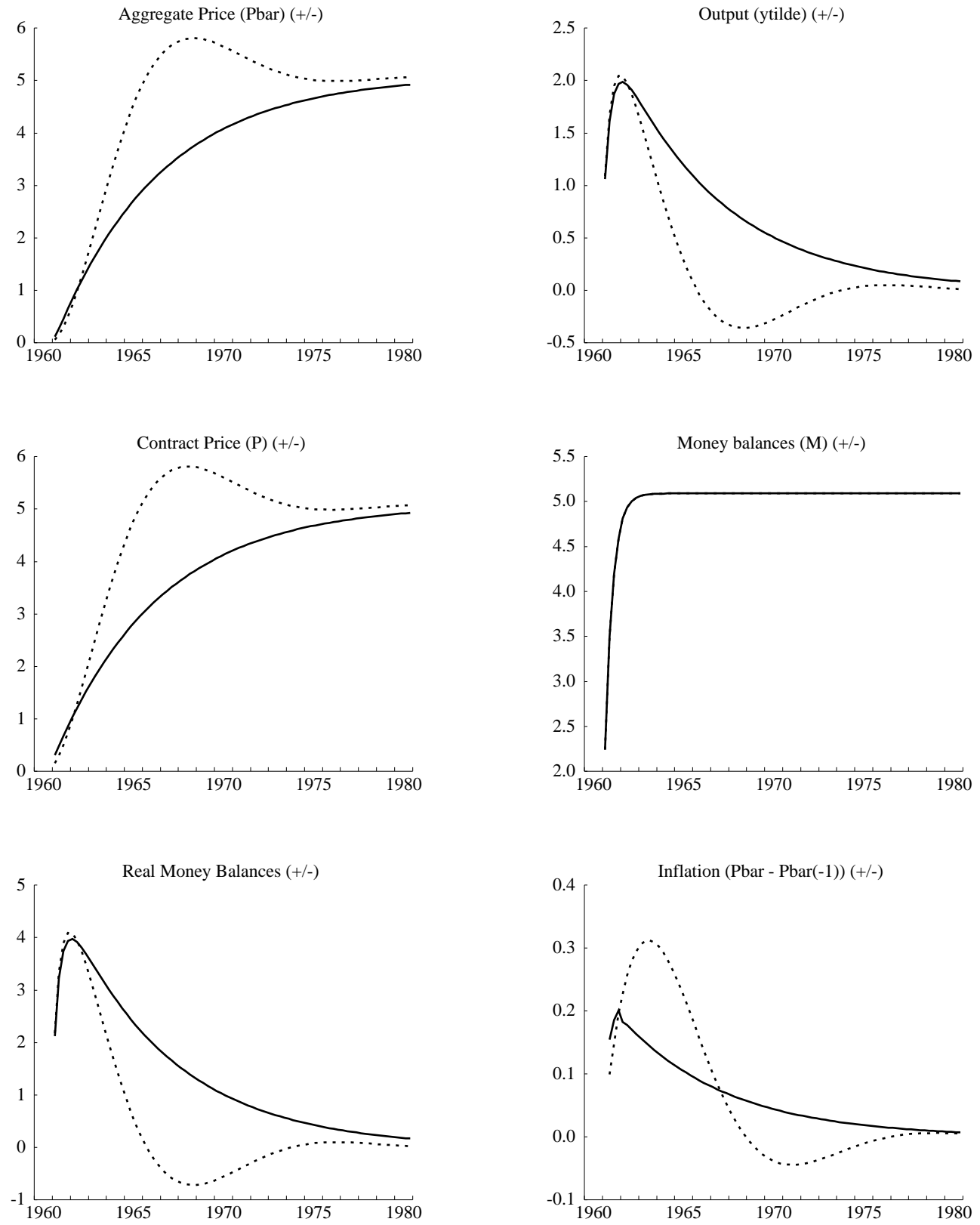

Solid: Standard Contracts

Dotted: Relative Contracts 
Figure 11: Response to an unannounced shock to the rate of growth of money supply.

Gamma $=0.04, \mathrm{~S}=0.08$

Percentage Change from Baseline
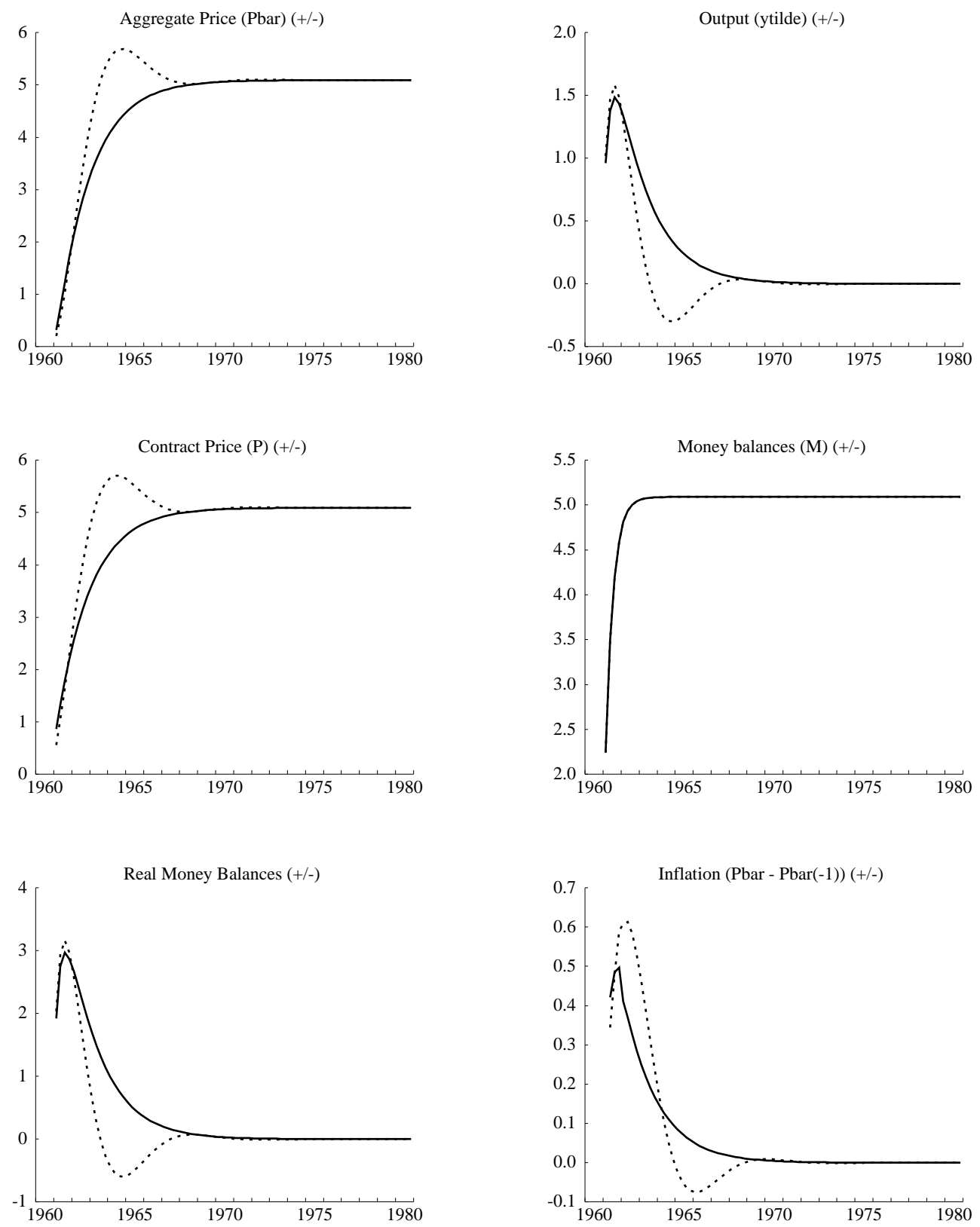

Solid: Standard Contracts

Dotted: Relative Contracts 


\section{References}

Bernanke, B. S. and A. S. Blinder (1992). The federal funds rate and the channels of monetary transmission. American Economic Review LXXXII, 901-21.

Blinder, A. (1994). On sticky prices: Academic theories meet the real world. In N. G. Mankiw (Ed.), Monetary Policy. University of Chicago Press.

Buiter, W. H. and I. Jewitt (1981). Staggered wage setting with real wage relativities: Variations on a theme of taylor. The Manchester School 49, 211-228. reprinted in W. H. Buiter (ed.), 1989, Macroeconomic theory and stabilization policy, Manchester: Manchester University Press.

Calvo, A. G. (1983, September). Staggered prices in a utility-maximizing framework. Journal of Monetary Economics 12, 383-398.

Calvo, G., O. Celasun, and M. Kumhof (2001, June). A theory of rational inflationary inertia. Unpublished manuscript, Stanford University.

Campbell, J. Y. and R. J. Shiller (1988). The dividend-price ratio and expectations of future dividends and discount factors. Review of Financial Studies I, 195-228.

Chari, V., P. J. Kehoe, and E. R. McGrattan (2000). Sticky price models of the business cycle: Can the contract multiplier solve the persistence problem? Econometrica $68(5), 1151-1179$.

Christiano, L. J., M. Eichenbaum, and C. L. Evans (1998, January). Modeling money. NBER Working Paper No.6371.

Christiano, L. J., M. Eichenbaum, and C. L. Evans (1999). Monetary policy shocks: what we have learned and to what end? In J. B. Taylor and M. Woodford (Eds.), Hanbook of Macroeconomics, pp. 65-148. Amsterdam: North Holland.

Coenen, G. and V. Wieland (2000, September). A small estimated euro area model with rational expectations and nominal rigidities. European Central Bank, working paper number 30 .

Cogley, T. and T. J. Sargent (2000). Evolving post-world war ii u.s. inflation dynamics. 
Unpublished manuscript.

Duke, J. and L. Usher (1998, September). Bls completes major expansion of industry productivity series. Monthly Labor Review, 35-51.

Erceg, C. J. and A. T. Levin (2001, June). Imperfect credibility and inflation persistence. FRB Finance and Economics Discussion Series.

Evans, M. and P. Wachtel (1977). Inflation regimes and the sources of inflation uncertainty. Journal of Money, Credit and Banking 25, 475-511.

Fuhrer, J. C. and G. R. Moore (1995, February). Inflation persistence. Quarterly Journal of Economics (440), 127-159.

Galí, J. and M. Gertler (1999, August). Inflation dynamics: A structural econometric analysis. Journal of Monetary Economics $44(2)$.

Galí, J., M. Gertler, and J. D. López-Salido (2001a). European inflation dynamics. European Economic Review 45, 1237-1270.

Galí, J., M. Gertler, and J. D. López-Salido (2001b, June). Notes on estimating the closed form of the hybrid new phillips curve. Unpublished paper, New York University.

Guerrieri, L. (2001, December). Inflation dynamics. International Finance Discussion Papers, Number 715, Board of Governors of the Federal Reserve System.

Harvey, A. (1981). The Econometric Analysis of Time Series (Second Edition ed.). London: Philip Allan.

Huang, K. and Z. Liu (2002). Staggered price-setting, staggered wage-setting, and business cycle persistence. Journal of Monetary Economics 49(2), 405-433.

Jadresic, E. (1999, May). Sticky prices: an empirical assessment of alternative models. International Monetary Fund Working Paper: WP/99/72.

King, R. G. and M. W. Watson (1994). The post-war U.S. Phillips curve: a revisionist econometric history. Carnegie Rochester Conference Series on Public Policy 41, $157-$ 219.

Mankiw, N. G. and R. Reis (2002, January). Sticky information versus sticky prices: a 
proposal to replace the new keynesian phillips curve. Manuscript, Harvard University; forthcoming in Quarterly Journal of Economics.

Phillips, A. (1958). The relation between unemployment and the rate of change of money wages in the united kingdom, 1861-1957. Economica 25, 283-299.

Roberts, J. M. (1997). Is inflation sticky. Journal of Monetary Economics 39, 173-196.

Rudd, J. and K. Whelan (2001). New-Keynesian Phillips curve. Board of Governors of the Federal Reserve System: International Finance Discussion Papers.

Sbordone, A. M. (2002). Prices and unit labor costs: A new test of price stickiness. Journal of Monetary Economics 49(2), 265-292.

Taylor, J. B. (1980). Aggregate dynamics and staggered contracts. Journal of Political Economy 88(1), 1-22.

Taylor, J. B. (2000). Low inflation, pass-through, and the pricing power of firms. European Economic Review 44, 1389-1408.

Yun, T. (1996). Nominal price rigidity, money supply endogeneity, and business cycles. Journal of Monetary Economics 37, 345-370. 


\section{A The equation for inflation under the setup of Taylor $(1980)$}

In a symmetric two-period setup, the log of the aggregate price level, $\bar{P}_{t}$, is given by:

$$
\bar{P}_{t}=\frac{1}{2}\left(P_{t}+P_{t-1}\right)
$$

where $P_{t}$ is the contract price. Equation (4), that governs the contract price, for a two period setup, can be rewritten as

$$
P_{t}=\frac{1}{2} P_{t-1}+\frac{1}{2} E_{t} P_{t+1}+\gamma\left(\tilde{y}_{t}+E_{t} \tilde{y}_{t+1}\right)
$$

where $\tilde{y}_{t}$ adjusts the contract for excess demand. Combining equation 22 and equation 23, one obtains:

$$
\bar{P}_{t}=\frac{1}{2}\left(\frac{1}{2} P_{t-1}+\frac{1}{2} E_{t} P_{t+1}+\frac{1}{2} P_{t-2}+\frac{1}{2} E_{t-1} P_{t}\right)+\frac{\gamma}{2}\left(\tilde{y}_{t}+E_{t} \tilde{y}_{t+1}+\tilde{y}_{t-1}+E_{t-1} \tilde{y}_{t}\right)
$$

Using equation 22 , equation 24 can be rewritten as:

$$
\bar{P}_{t}=\frac{1}{2}\left(E_{t} \bar{P}_{t+1}+\bar{P}_{t-1}\right)+\frac{\gamma}{2}\left(\tilde{y}_{t}+E_{t} \tilde{y}_{t+1}+\tilde{y}_{t-1}+E_{t-1} \tilde{y}_{t}\right)-\frac{1}{4} \epsilon_{t}
$$

where $\epsilon_{t}$ is a forecast error such that $E_{t-1} w_{t}=w_{t}-\epsilon_{t}$.

To reformulate equation 25 in terms of inflation, notice that since the price level, $\bar{P}_{t}$, is in $\log$ form, the inflation at time $t, \pi_{t}$, is given by $\pi_{t}=\bar{P}_{t}-\bar{P}_{t-1}$. Therefore, using equation 25, subtracting $\bar{P}_{t-1}$ from both sides:

$$
\bar{P}_{t}-\bar{P}_{t-1}=\frac{1}{2}\left(E_{t} \bar{P}_{t+1}-\bar{P}_{t-1}\right)+\frac{\gamma}{2}\left(\tilde{y}_{t}+E_{t} \tilde{y}_{t+1}+\tilde{y}_{t-1}+E_{t-1} \tilde{y}_{t}\right)-\frac{1}{4} \epsilon_{t}
$$

Rearranging the terms in the equation above, and adding and subtracting $\frac{1}{2} P_{t}$ :

$$
\begin{aligned}
\pi_{t}= & \frac{1}{2}\left(E_{t} \bar{P}_{t+1}-\bar{P}_{t}+\bar{P}_{t}-\bar{P}_{t-1}\right) \\
& +\frac{\gamma}{2}\left(\tilde{y}_{t}+E_{t} \tilde{y}_{t+1}+\tilde{y}_{t-1}+E_{t-1} \tilde{y}_{t}\right)-\frac{1}{4}\left(\epsilon_{t}\right)
\end{aligned}
$$

which, in turn, can be rewritten as:

$$
\pi_{t}=\frac{1}{2}\left(E_{t} \pi_{t+1}+\pi_{t}\right)+\frac{\gamma}{2}\left(\tilde{y}_{t}+E_{t} \tilde{y}_{t+1}-\tilde{y}_{t-1}+E_{t-1} \tilde{y}_{t}\right)-\frac{1}{4}\left(\epsilon_{t}\right)
$$

Therefore, collecting terms in equation 27 yields:

$$
\pi_{t}=E_{t} \pi_{t+1}+\gamma\left(\tilde{y}_{t}+E_{t} \tilde{y}_{t+1}+\tilde{y}_{t-1}+E_{t-1} \tilde{y}_{t}\right)-\frac{1}{2} \epsilon_{t}
$$




\section{B Mapping s into contract weights}

Expanding equation (7), one obtains

$$
\begin{aligned}
\bar{P}_{t}= & \theta_{1} P_{t} \\
& +\frac{\theta_{2}}{2}\left(P_{t}+P_{t-1}\right) \\
& +\frac{\theta_{3}}{3}\left(P_{t}+P_{t-1}+P_{t-2}\right) \\
& +\frac{\theta_{4}}{4}\left(P_{t}+P_{t-1}+P_{t-2}+P_{t-3}\right)
\end{aligned}
$$

But $\theta_{4}=1-\theta_{1}-\theta_{2}-\theta_{3}$. Using equation (8), combined with the equation above, one can see that

$$
\begin{aligned}
f_{0} & =\theta_{1}+\frac{1}{2} \theta_{2}+\frac{1}{3} \theta_{3}+\frac{1}{4}\left(1-\theta_{1}-\theta_{2}-\theta_{3}\right) \\
f_{1} & =\frac{1}{2} \theta_{2}+\frac{1}{3} \theta_{3}+\frac{1}{4}\left(1-\theta_{1}-\theta_{2}-\theta_{3}\right) \\
f_{2} & =\frac{1}{3} \theta_{3}+\frac{1}{4}\left(1-\theta_{1}-\theta_{2}-\theta_{3}\right)
\end{aligned}
$$

Which leads to

$$
\left(\begin{array}{l}
\theta_{1} \\
\theta_{2} \\
\theta_{3}
\end{array}\right)=\left(\begin{array}{ccc}
\frac{3}{4} & \frac{1}{4} & \frac{1}{12} \\
-\frac{1}{4} & \frac{1}{4} & \frac{1}{12} \\
-\frac{1}{4} & -\frac{1}{4} & \frac{1}{12}
\end{array}\right)^{-1}\left(\left(\begin{array}{l}
f_{0} \\
f_{1} \\
f_{2}
\end{array}\right)-\frac{1}{4}\left(\begin{array}{c}
1 \\
1 \\
1
\end{array}\right)\right)
$$

where $f_{i}=0.25+(1.5-i) s$, for $0<s \leq \frac{1}{6}$

\section{VAR estimation results}

The VAR for detrended output, the interest rate and inflation, takes the form:

$$
\begin{aligned}
\tilde{Y}_{t} & =C_{c, 1}+\sum_{i=1}^{3} C_{y, 1, i} \tilde{Y}_{t-i}+C_{r, 1, i} r_{t-i}+C_{\pi, 1, i} \pi_{t-i}+\epsilon_{y, t} \\
r_{t} & =C_{c, 2}+\sum_{i=1}^{3} C_{y, 2, i} \tilde{Y}_{t-i}+C_{r, 2, i} r_{t-i}+C_{\pi, 2, i} \pi_{t-i}+\epsilon_{r, t} \\
\pi_{t} & =C_{c, 3}+\sum_{i=1}^{3} C_{y, 3, i} \tilde{Y}_{t-i}+C_{r, 3, i} r_{t-i}+C_{\pi, 3, i} \pi_{t-i}+\epsilon_{\pi, t}
\end{aligned}
$$


The estimation results for the sample 1980 - 2001 are reported in Table 5. Table 6 reports the restricted estimates, over the same sample excluding the constant term from each equation. A likelihood ratio test confirms the validity of the restriction. The log likelihood for the unrestricted VAR is 903, while for the restricted VAR the log likelihood is 901 . The null hypothesis that the restriction is valid fails to be rejected at standard significance levels. 
Table 5: VAR Parameter Estimates (constant included), Regression 1 (1980q1 - 2001q4)

\begin{tabular}{|c|c|c|c|c|}
\hline Parameter & Estimate & Error & t-statistic & P-value \\
\hline$C_{c, 1}$ & $.110 \mathrm{E}-02$ & $.197 \mathrm{E}-02$ & .558 & {$[.577]$} \\
\hline$C_{y, 1,1}$ & .913 & .101 & 9.01 & {$[.000]$} \\
\hline$C_{y, 1,2}$ & .197 & .134 & 1.47 & [.142] \\
\hline$C_{y, 1,3}$ & -.230 & .0968 & -2.38 & {$[.017]$} \\
\hline$C_{r, 1,1}$ & .212 & .0974 & 2.17 & {$[.030]$} \\
\hline$C_{r, 1,2}$ & -.500 & .133 & -3.77 & {$[.000]$} \\
\hline$C_{r, 1,3}$ & .310 & .0915 & 3.39 & {$[.001]$} \\
\hline$C_{\pi, 1,1}$ & -.132 & .0726 & -1.82 & {$[.068]$} \\
\hline$C_{\pi, 1,2}$ & .044 & .0684 & .647 & {$[.518]$} \\
\hline$C_{\pi, 1,3}$ & $-.306 \mathrm{E}-02$ & .0692 & -.0443 & {$[.965]$} \\
\hline$C_{c, 2}$ & $.409 \mathrm{E}-02$ & $.220 \mathrm{E}-02$ & 1.86 & {$[.063]$} \\
\hline$C_{y, 2,1}$ & 1.11 & .109 & 10.3 & {$[.000]$} \\
\hline$C_{y, 2,2}$ & .0905 & .150 & .605 & {$[.545]$} \\
\hline$C_{y, 2,3}$ & -.228 & .108 & -2.10 & {$[.035]$} \\
\hline$C_{r, 2,1}$ & 1.21 & .0805 & 15.1 & {$[.000]$} \\
\hline$C_{r, 2,2}$ & -.569 & .148 & -3.84 & {$[.000]$} \\
\hline$C_{r, 2,3}$ & .245 & .102 & 2.40 & {$[.016]$} \\
\hline$C_{\pi, 2,1}$ & .0193 & .0810 & .238 & {$[.812]$} \\
\hline$C_{\pi, 2,2}$ & .392 & .0760 & 5.14 & {$[.000]$} \\
\hline$C_{\pi, 2,3}$ & -.103 & .0771 & -1.34 & [.180] \\
\hline$C_{c, 3}$ & $.156 \mathrm{E}-02$ & $.298 \mathrm{E}-02$ & .524 & {$[.600]$} \\
\hline$C_{y, 3,1}$ & .125 & .153 & .812 & {$[.416]$} \\
\hline$C_{y, 3,2}$ & -.513 & .200 & -2.55 & {$[.011]$} \\
\hline$C_{y, 3,3}$ & .150 & .146 & 1.03 & {$[.303]$} \\
\hline$C_{r, 3,1}$ & .600 & .147 & 4.08 & {$[.000]$} \\
\hline$C_{r, 3,2}$ & -.675 & .227 & -2.98 & {$[.003]$} \\
\hline$C_{r, 3,3}$ & -.0135 & .138 & -.0978 & {$[.922]$} \\
\hline$C_{\pi, 3,1}$ & .391 & .110 & 3.57 & {$[.000]$} \\
\hline$C_{\pi, 3,2}$ & .198 & .103 & 1.92 & {$[.055]$} \\
\hline$C_{\pi, 3,3}$ & .147 & .104 & 1.40 & {$[.160]$} \\
\hline
\end{tabular}

Number of observations $=85$ Log likelihood $=903.188$

Equation: $\tilde{y}$ Variance of residuals $=.356228 \mathrm{E}-04$ Std. error of regression $=.596849 \mathrm{E}-02 \mathrm{R}$-squared $=$ .846797

Equation: $r$ Variance of residuals $=.443094 \mathrm{E}-04$ Std. error of regression $=.665653 \mathrm{E}-02$ R-squared $=$ .943060

Equation: $\pi$ Variance of residuals $=.812260 \mathrm{E}-04$ Std. error of regression $=.901254 \mathrm{E}$-02 R-squared $=$ .787872 
Table 6: VAR Parameter Estimates (constant excluded), Regression 1 (1980q1 - 2001q4)

\begin{tabular}{|c|c|c|c|c|}
\hline Parameter & Estimate & Error & t-statistic & P-value \\
\hline$C_{y, 1,1}$ & .917142 & .101471 & 9.03844 & {$[.000]$} \\
\hline$C_{y, 1,2}$ & .192108 & .134050 & 1.43310 & {$[.152]$} \\
\hline$C_{y, 1,3}$ & -.235178 & .096710 & -2.43179 & {$[.015]$} \\
\hline$C_{r, 1,1}$ & .228172 & 092938 & 2.45510 & {$[.014]$} \\
\hline$C_{r, 1,2}$ & -.511142 & .131610 & -3.88378 & {$[.000]$} \\
\hline$C_{r, 1,3}$ & .325152 & .087388 & 3.72080 & {$[.000]$} \\
\hline$C_{\pi, 1,1}$ & -.132020 & .072761 & -1.81443 & {$[.070]$} \\
\hline$C_{\pi, 1,2}$ & .041451 & .068358 & .606379 & {$[.544]$} \\
\hline$C_{\pi, 1,3}$ & -.014888 & .065960 & -.225713 & {$[.821]$} \\
\hline$C_{y, 2,1}$ & .263326 & .115230 & 2.28523 & {$[.022]$} \\
\hline$C_{y, 2,2}$ & .072040 & .152226 & .473242 & {$[.636]$} \\
\hline$C_{y, 2,3}$ & -.243371 & 109823 & -2.21604 & {$[.027]$} \\
\hline$C_{r, 2,1}$ & 1.17428 & .105539 & 11.1265 & {$[.000]$} \\
\hline$C_{r, 2,2}$ & -.608304 & .149455 & -4.07016 & {$[.000]$} \\
\hline$C_{r, 2,3}$ & .302533 & .099237 & 3.04859 & {$[.002]$} \\
\hline$C_{\pi, 2,1}$ & .020595 & .082627 & .249247 & {$[.803]$} \\
\hline$C_{\pi, 2,2}$ & .382025 & .077626 & 4.92132 & {$[.000]$} \\
\hline$C_{\pi, 2,3}$ & -.147313 & .074903 & -1.96671 & {$[.049]$} \\
\hline$C_{y, 3,1}$ & .129185 & .153191 & .843291 & [.399] \\
\hline$C_{y, 3,2}$ & -.226571 & .202375 & -1.11956 & {$[.263]$} \\
\hline$C_{y, 3,3}$ & .144489 & .146003 & .989633 & {$[.322]$} \\
\hline$C_{r, 3,1}$ & .623527 & .140308 & 4.44400 & {$[.000]$} \\
\hline$C_{r, 3,2}$ & -.526763 & .198690 & -2.65117 & {$[.008]$} \\
\hline$C_{r, 3,3}$ & $.834549 \mathrm{E}-02$ & .131929 & .063257 & {$[.950]$} \\
\hline$C_{\pi, 3,1}$ & .391898 & .109847 & 3.56766 & {$[.000]$} \\
\hline$C_{\pi, 3,2}$ & .193988 & .103200 & 1.87973 & {$[.060]$} \\
\hline$C_{\pi, 3,3}$ & .129899 & .099579 & 1.30448 & {$[.192]$} \\
\hline
\end{tabular}

Number of observations $=85 \log$ likelihood $=901.429$

EQ1 $: \tilde{y}$ Variance of residuals $=.357534 \mathrm{E}-04$ Std. error of regression $=.597941 \mathrm{E}-02$ R-squared $=$ .846296

Equation: $r$ Variance of residuals $=.461063 \mathrm{E}-04$ Std. error of regression $=.679017 \mathrm{E}-02 \mathrm{R}$-squared $=$ .942303

Equation: $\pi$ Variance of residuals $=.814885 \mathrm{E}-04$ Std. error of regression $=.902710 \mathrm{E}-02 \mathrm{R}$-squared $=$ .787436 